\title{
PERAN JOB DEMANDS DAN JOB RESOURCES TERHADAP WORK- FAMILY ENRICHMENT PADA GURU DI SEKOLAH X
}

\author{
Florensia Louhenapessy $^{1}$, Rita Markus Idulfilastri ${ }^{2}$, P. Tommy Y. S. Suyasa ${ }^{3}$ \\ ${ }^{1}$ Program Studi Magister Psikologi, Universitas Tarumanagara, Jakarta \\ Email: FlorensiaGL@gmail.com \\ ${ }^{2}$ Fakultas Psikologi, Universitas Tarumanagara, Jakarta \\ Email: ritamarkus@fpsi.untar.ac.id \\ ${ }^{3}$ Fakultas Psikologi, Universitas Tarumanagara, Jakarta \\ Email: tommys@fpsi.untar.ac.id
}

Masuk : 04-08-2020, revisi: 26-10-2020, diterima untuk diterbitkan : 31-10-2020

\begin{abstract}
The teacher plays two main roles in his life, namely the role in work and in the family. The implementation of these two roles does not always cause conflict, but can improve the quality of life of teachers. Teacher job conflicts are closely related to job demand and job resources. Therefore, the purpose of this study is to see how the role of job demands and job resources on work-family enrichment in teachers. Work-family enrichment is enrichment obtained from individual experiences at work towards the welfare of family life, or vice versa. Job demands are defined as identical job demands with various pressures on the job (job stressor). Examples of job demands on teachers are the number of students who exceed the capacity in the classroom, the addition of subject matter outside of the teacher's interest / competence, the demand to adjust science to the times. Job resources are physical, social, and organizational aspects that serve as support or resources to achieve work goals. With the existence of job resources, job demands can be resolved. Psychologically, solving work demands based on available resources will stimulate the individual to grow and develop personally, in this case the personal growth of the individual has implications for increasing his welfare in working / family life. Participants in this study were 43 teachers in School X. Analysis of research results using multiple regression showed that job demands and job resources together played a role in predicting an increase in work-family enrichment by $12.5 \%$. The implication of the results of this study is that various demands on work supported by resources at work can improve welfare in working life / family life.
\end{abstract}

Keywords: work-family enrichment, job demands, job resources.

\begin{abstract}
ABSTRAK
Guru menjalankan dua peran utama dalam kehidupannya yaitu peran di pekerjaan dan keluarga. Menjalankan dua peran tersebut tidak selalu menimbulkan konflik, namun justru bisa meningkatkan kualitas hidup guru. Konflik pekerjaan guru sangat berhubungan dengan job demand dan job resources. Oleh karena itu, tujuan penelitian adalah untuk melihat bagaimana peran job demands dan job resources terhadap work-family enrichment pada guru. Workfamily enrichment merupakan pengayaan yang diperoleh dari pengalaman-pengalaman individu di pekerjaan terhadap kesejahteraan kehidupan berkeluarga, atau sebaliknya. Job demands didefinisikan sebagai tuntutantuntutan pekerjaan yang indentik dengan berbagai tekanan dalam pekerjaan (job stressor). Contoh dari job demands pada guru adalah jumlah siswa yang melebihi kapasitas di dalam kelas, penambahan materi pelajaran di luar minat/kompetensi guru, tuntutan untuk menyesuaikan ilmu pengetahuan dengan perkembangan zaman. Job resources adalah aspek-aspek fisik, sosial, maupun organisasi yang berfungsi sebagai pendukung atau sumber daya untuk mencapai tujuan pekerjaan. Dengan adanya job resources maka job demands dapat terselesaikan. Secara psikologis, penyelesaian job demands berdasarkan job resources yang dimiliki akan menstimulasi individu untuk bertumbuh dan berkembang secara personal, dalam hal ini pertumbuhan personal yang dimiliki individu berimplikasi pada work-family enrichment. Partisipan pada penelitian ini adalah guru yang berjumlah 43 orang di Sekolah X. Analisis hasil penelitian yang menggunakan multiple regression menunjukan bahwa job demands dan job resources bersama-sama berperan memprediksi peningkatan work-family enrichment sebesar $12,5 \%$. Implikasi dari hasil penelitian ini bahwa berbagai tuntutan dalam pekerjaan yang di dukung dengan sumber daya dalam pekerjaan dapat meningkatkan kesejahteraan dalam kehidupan berkerja dan berkeluarga.
\end{abstract}

Kata Kunci: work-family enrichment, job demands, job resources. 


\section{PENDAHULUAN}

\section{Latar Belakang}

Keluarga merupakan satuan sistem sosial terkecil. Kehidupan individu bermula dari dalam keluarga, sehingga keluarga merupakan sumber utama bagi kehidupan individu dan masyarakat secara keseluruhan. Begitu juga dalam hal pendidikan anak generasi penerus. Siswa harus menempatkan guru sebagai keluarganya. Keluarga mempunyai fungsi sebagai pengembangan agama, personal, sosial, budaya, ekonomi, pendidikan dan pengembangan keturunan. Karena itulah keluarga memainkan peranan fundamental bagi kesuksesan individu.

Guru menjalankan dua peran utama dalam kehidupannya yaitu peran di pekerjaan dan keluarga. Menjalankan dua peran tersebut tidak selalu menimbulkan konflik, namun justru bisa menambah pengalaman dan meningkatkan kualitas hidup guru yang menjalaninya. Work-family enrichment merupakan pengalaman-pengalaman dalam satu peran di pekerjaan meningkatkan kualitas hidup pada peran yang lain (Greenhaus \& Powell, 2006), dalam penelitian ini peran guru dan peran di dalam peran di keluarganya. Dicontohkan oleh Carlson, et al. (2006) ketika seorang di dalam pekerjaannya mendapat keterampilan menangani konflik, kemudian pengalaman tersebut dipakainya ketika menyelesaikan konflik dengan keluarganya, dengan anak-anak, pasangan hidup atau dengan anggota keluarga lainnya.

Tentunya agar terjadi work-family enrichment tidak terlepas dari peran seorang guru. Dengan berpedoman pada JD-R Theory (Job Demand-Resource Theory) (Bakker \& Demerouti, 2014) bahwa pada setiap pekerjaan terdapat pengaruh tekanan dan motivasi, dinamakan job demands dan job resources. (Schaufeli \& Bakker, 2004) menyatakan job demands adalah aspek-aspek fisik, psikologis, sosial dan organisasi dari pekerjaan yang membutuhkan usaha dalam bentuk fisik, kognitif maupun emosional secara terus menerus. Oleh karena itu, hal ini diasosiasikan dengan biaya fisik dan atau psikologis tertentu. Meskipun demikian, job demands tidak selalu menghasilkan efek negatif, tetapi job demands dapat berubah menjadi stres kerja bila disertai dengan tuntutan yang membutuhkan usaha yang besar, yang pada akhirnya dapat menimbulkan efek negatif seperti depresi, kecemasan, dan burnout.

Hasil perbandingan guru di DKI Jakarta memperlihatkan rata-rata 1 orang guru SD menangani sebanyak 22 siswa, rata-rata 1 orang guru SMP menangani 19 siswa, rata-rata 1 orang guru SMA menangani 9 siswa dan rata-rata 1 orang guru SMK menangani 21 siswa. Dengan perbandingan guru dan siswa terlihat bahwa jumlah guru dan murid sudah proporsional, yaitu terpenuhinya perbandingan guru dan siswa ideal yaitu satu orang guru mengajar dengan kapasitas maksimal 25 siswa. Namun kenyataan di lapangan satu kelas biasanya terdiri lebih dari 25 siswa setiap kelas. Hal ini terjadi karena tidak meratanya penempatan guru pada setiap sekolah dan terdapat jumlah siswa yang lebih banyak terutama untuk sekolah-sekolah favorit. Akibatnya masih terdapat beban kerja guru yang berlebihan pada satu sekolah.

Tuntutan guru menjadi bertambah karena guru mengajar lebih dari satu mata pelajaran. Padahal belum tentu mata pelajaran tersebut sesuai dengan pengetahuan yang dimilikinya. Hal ini tentu saja akan menjadi beban tambahan guru karena guru harus belajar dan mempersiapkan materi. Walaupun dalam UU No. 14 Tahun 2005 Tentang Guru dan Dosen menyebutkan bahwa guru adalah agen pembelajaran yang harus menjadi fasilitator, motivator, dan pemberi insipirasi belajar bagi peserta didik namun seringkali penambahan mata pelajaran merupakan beban guru. 
Ditinjau dari kesejahteraan guru, ternyata tingkat kesejahteraan guru-guru kita cukup memprihatinkan. Penghasilan para guru, dipandang masih jauh dari mencukupi, apalagi bagi mereka yang masih berstatus sebagai guru bantu atau guru honorer. Kondisi seperti ini, membuat sebagian guru untuk mencari penghasilan tambahan, di luar dari tugas pokok mereka sebagai pengajar, termasuk berbisnis di lingkungan sekolah tempat guru mengajar. Kesejahteraan guru berpengaruh terhadap pekerjaan guru, iika kesejahteaan terpenuhi, guru akan konsentrasi mengajar. Tentunya, berdampak pada meningkatkan profesionalisme guru. Beban kerja guru dalam satu minggu menurut Permendikbud Nomor 15 Tahun 2018 pasal 2 yaitu 40 jam per minggu yang terdiri 37,5 jam sebagai jam kerja efektif sedangkan sisanya 2,5 jam adalah jam istirahat.

Job demands dapat mengakibatkan kelelahan dan keluhan kesehatan lainnya, sehingga berkaitan dengan tekanan pada pekerjaan. Sebaliknya, job resources berkaitan dengan hal-hal yang secara potensial memotivasi karyawan sehingga berdampak pada hasil yang positif seperti peningkatan kepuasan kerja dan keterikatan kerja (Bakker \& Demerouti, 2014).

Penelitian yang terkait dengan subyek penelitian yaitu guru, telah dilakukan di Finlandia terhadap 805 guru SD, SMP dan SMK. Ditemukan hasil bahwa dukungan pengawas, inovasi, penghargaan, dan iklim organisasi sebagai dimensi-dimensi job demands merupakan hal penting yang membantu para guru berinteraksi dengan siswa (Bakker, Hakanen, Demerouti, Xanthopoulou, 2007). Menurut Greenhaus dan Powell (2006) dengan meningkatnya sumber daya merupakan aset untuk memecahkan masalah atau menjalani situasi yang lebih menantang. Meningkatnya job resources diperoleh dari pengalaman mengatasi job demands sebagai guru dan memanfaatkan job resources yang ada di sekolah dengan baik.

Work-family enrichment dikonsepkan oleh Greenhaus dan Powell (2006) sebagai suatu keadaan tentang sejauh mana pengalaman dalam satu peran meningkatkan kualitas hidup di peran lainnya. Konsep tersebut diaplikasikan pada penelitian ini menjadi sejauh mana pengalaman peran sebagai guru sekolah meningkatkan kualitas di kehidupan keluarga guru. Dipertegas oleh Greenhaus dan Beutell (1985), konsep work-family enrichment berfokus pada hubungan positif dari kedua peran tersebut, artinya jika peran guru sekolah positif maka peran di keluarga juga positif. Dan hal dijelaskan oleh guru sekolah yang memiliki mean variabel Work-family enrichment yang sangat tinggi. Dengan kata lain, peran sebagai guru memperkaya peran di keluarga guru.

Penggunaan job demands dan job resources sebagai variabel independen didasari oleh asumsi teori JD-R. Dikatakan bahwa seluruh lingkungan kerja atau karakteristik pekerjaan dapat diimplementasikan dengan menggunakan dua kategori yang berbeda, yaitu job demands dan job resources. Diperkuat oleh Carlson, et all. (2011) kepuasan kerja akan memberikan efek langsung terhadap work-family enrichment. Dengan kata lain, jika guru merasakan puas terhadap pekerjaannya maka akan memberikan efek terhadap perannya di keluarga. Hasil penelitian ditinjau dari sisi job demands terlihat guru memiliki tanggung jawab kerja yang berlebihan sehingga jika dihubungkan dengan work-family enrichment menjadi berkurang. Namun pada dasarnya guru dapat mengatasi tuntutan-job demandsnya bahkan hasil mean variabel job demands dipersepsikan sangat tinggi ketika menghasilkan ide-ide baru dan menyelesaikan masalah sulit. Dengan kata lain, guru bertanggung jawab terhadap job demandsnya walaupun memberikan efek negatif pengayaan peran di dalam keluarganya. 
Pada job demands guru ternyata dimensi cognitive demands merupakan dimensi yang paling tinggi diantara dimensi lainnya. Artinya guru sangat siap untuk menanggani yang membutuhkan pengolahan kognitif. Hal ini sejalan dengan penelitian Lestari \& Zamralita (2017) yang menyatakan bahwa cognitive demand merupakan dimensi job demands yang paling sering dialami pegawai Institusi $\mathrm{X}$ di DKI Jakarta. Walaupun dalam hal ini tidak langsung menunjukkan partisipan yang sama antara pegawai institusi dengan guru.

Job resources sebagai bagian yang tak terpisahkan dari job demands, memberikan efek positif terhadap work-family enrichment. Walaupun job resources dipersepsikan sangat tinggi oleh guru, tapi dimensi meaning of work dipersepsikan rendah. Ternyata guru belum merasakan penting pekerjaan sebagai pendidik. Sedangkan dimensi yang tertinggi adalah supervisory coaching. Guru masih memerlukan pengarahan dari atasannya untuk melaksanakan pekerjaannya.

Penjelasan dimensi meaning of work dipersepsikan rendah oleh guru, kemungkinan disebabkan oleh adanya perbedaan dari sisi usia. Artinya belum ada kesamaan dalam memaknai pekerjaan sebagai guru. Oleh karena itu maka guru masih bergantung pada arahan atasannya untuk mengatasi kebingungan perannya sebagai guru. Hasil pengamatan peneliti kondisi ini sesuai dengan yang terjadi di Sekolah X.

Penelitian ini ditujukan untuk melihat peran job demands dan job resources terhadap workfamily enrichment pada guru Sekolah X.

\section{METODE PENELITIAN}

\section{Partisipan dan Prosedur Penelitian}

Teknik pengambilan sampel menggunakan purposive sampling artinya sampel yang diambil sesuai dengan karakteristik yang ditetapkan dalam penelitian. Berdasarkan teknik pengambilan sampel di atas maka sampel yang akan dipergunakan dalam penelitian ini adalah seluruh guru yang mengajar yaitu sebanyak 43 orang. Penelitian ini dilakukan pada guru Sekolah X dengan menggunakan kuesioner via online melalui google form. Kuesioner online tersebut dikirim langsung kepada Guru dan dikembalikannya dengan secara online pula. Kuesioner yang dibagikan terdiri atas tiga bagian. Pertama adalah informed consent menjelaskan mengenai tujuan pengisian kuesioner. Bagian kedua adalah variabel kontrol yang berisi data diri dari partisipan. Bagian ketiga adalah alat ukur kuesioner mengenai job demands, job resources dan work-family enrichment.

Karakteristik partisipan adalah guru yang mengajar di Sekolah X berstatus guru tetap atau guru honorer dan minimal telah bekerja sebagai guru selama satu tahun. Jenis kelamin partisipan lakilaki 6 orang $(13,96 \%)$, perempuan 37 orang $(86,04 \%)$. Usia partisipan < 25 tahun 10 orang (23,35\%), 25 - 40 tahun 30 orang $(69,8 \%)$ dan $>40$ tahun 3 orang $(6,85 \%)$. Berdasarkan masa kerja $<2$ tahun 18 orang (39,5\%), 2 - 4 tahun $(18,6 \%),>4$ tahun 18 orang (41,9\%). Berdasarkan jenjang Pendidikan SMU/SMK 2 orang (4,7\%), Diploma 1 orang (2,3\%), S1 40 orang $(93 \%)$, dan tidak ada partisipan yang S2. Berdasarkan gaji setiap bulan, $<$ Rp. 5.000 .000 32 orang $(74,4 \%)$ dan Rp. 5.000.000 - Rp. 10.000.000 11 orang (25,6\%).

\section{Instrumen Penelitian}

Work-family enrichment dilakukan dengan menggunakan alat ukur yang disusun oleh Carlson, et al. (2006) bernama Work family enrichment Scale. Terdapat 6 dimensi yaitu work to family development, work to family affect, work to family capital, family to work development, family to work affect dan family to work efficiency. Dimensi work to family development diukur dengan 3 
butir. Contoh butir: "Saya perlu bantuan orang lain untuk mendapatkan sudut pandang yang berbeda agar saya menjadi anggota keluarga yang lebih baik" . Dimensi work to family affect diukur dengan 3 butir. Contoh butir: "Saya menempatkan suasana hati saya agar saya menjadi anggota keluarga yang lebih baik". Dimensi work to family capital diukur dengan 3 butir. Contoh butir: "Saya merasa terpenuhi secara pribadi dan ini membuat saya menjadi anggota keluarga yang lebih baik" . Dimensi family to work development dengan 3 butir. Contoh butir: "Saya perlu bantuan orang lain untuk mendapatkan pemahaman tentang guru agar saya menjadi guru yang lebih baik”. Dimensi family to work affect diukur dengan 3 butir. Contoh butir: Saya menempatkan suasana hati saya agar saya menjadi guru yang lebih baik" . Dimensi family to work efficiency diukur dengan 3 butir. Contoh butir: "Saya diharuskan untuk tidak membuang-buang waktu di tempat kerja dan itu membuat saya menjadi guru yang lebih baik" . Reliabilitas alat ukur work-family enrichment sebesar 0,856.

Job demands dilakukan dengan menggunakan alat ukur yang disusun oleh Pejtersen et al. (2010) pada COPSPQ II. Job demands mempunyai 4 dimensi yaitu quantitative demands, cognitive demands, emotional demands dan demands for hiding emotions. Dimensi quantitave demand diukur dengan 4 butir. Contoh butir: "Apakah beban kerja Anda tidak merata sehingga menumpuk?" . Dimensi cognitive demands diukur dengan 3 butir. Contoh butir: "Apakah pekerjaan Anda menuntut Anda untuk menghasilkan ide-ide baru?" . Dimensi emotional demands diukur dengan 4 butir. Contoh butir: "Apakah pekerjaan Anda menempatkan Anda dalam situasi yang mengganggu secara emosional?” . Dimensi demand for hiding emotions diukur dengan 3 butir. Contoh butir: "Apakah Anda diharuskan memperlakukan semua orang dengan setara, meskipun Anda tidak menyukainya?” . Reliabilitas alat ukur job demands sebesar 0,735 .

Job resources dilakukan dengan menggunakan alat ukur yang disusun oleh Pejtersen, et al. (2010) pada COPSPQ II dan Schaufeli \& Bakker (2004). Terdiri dari 4 dimensi yaitu meaning of work, feedback, social support dan supervisory coaching. Dimensi meaning of work diukur dengan 3 butir. Contoh butir: “Apakah pekerjaan Anda bermakna?” . Dimensi feedback diukur dengan 3 butir. Contoh butir: "Apakah pekerjaan Anda menawarkan peluang untuk pertumbuhan dan perkembangan pribadi?”. Dimensi Social support diukur dengan 3 butir. Contoh butir: "Seberapa sering Anda mendapatkan bantuan dan dukungan dari teman Anda?" . Dimensi supervisory coaching diukur dengan 2 butir. Contoh butir: "Atasan saya menggunakan pengaruhnya untuk membantu saya memecahkan masalah di tempat kerja” . Reliabilitas alat ukur job resources sebesar 0,747 .

\section{HASIL DAN PEMBAHASAN}

Penelitian ini memiliki tiga variabel yaitu: (1) Work-family enrichment; (2) Job demands; dan (3) Job resources.

\section{Gambaran Work-Family Enrichment}

Berikut ini penjelasan variabel work-family enrichment (skala 1-5) pada tabel berikut: 
Tabel 1. Gambaran mean Variabel work-family enrichment

\begin{tabular}{|c|c|c|c|c|c|c|}
\hline No & $\begin{array}{l}\text { Variabel/ } \\
\text { Dimensi }\end{array}$ & $\begin{array}{c}\text { Nilai } \\
\text { Minimum }\end{array}$ & $\begin{array}{c}\text { Nilai } \\
\text { Maksimum }\end{array}$ & Mean & $\begin{array}{c}\text { Std. } \\
\text { Deviation }\end{array}$ & Kategori \\
\hline & $\begin{array}{l}\text { Work-family } \\
\text { enrichment }\end{array}$ & 2,610 & 4,890 & 3,939 & 0,513 & Sangat tinggi \\
\hline 1. & $\begin{array}{c}\text { Work to family } \\
\text { development }\end{array}$ & 2,000 & 5,000 & 3,752 & 0,839 & Sangat tinggi \\
\hline 2. & Work to family affect & 2,000 & 5,000 & 3,868 & 0,810 & Sangat tinggi \\
\hline 3. & Work to family capital & 1,670 & 5,000 & 3,589 & 0,890 & Sangat tinggi \\
\hline 4. & $\begin{array}{c}\text { Family to work } \\
\text { development }\end{array}$ & 2,670 & 5,000 & 4,302 & 0,650 & Sangat tinggi \\
\hline 5 & Work to work affect & 2,000 & 5,000 & 3,899 & 0,841 & Sangat tinggi \\
\hline 6. & $\begin{array}{c}\text { Family to work } \\
\text { efficiency }\end{array}$ & 2,670 & 5,000 & 4,225 & 0,654 & Sangat tinggi \\
\hline
\end{tabular}

Berdasarkan tabel diatas skor mean empirik work-family enrichment sebesar 3,939 termasuk kedalam kategori sangat tinggi. Hal ini berarti bahwa sebagian besar guru memiliki pengayaan terhadap keluarga di dalam pekerjaannya. Berdasarkan ke enam dimensi ternyata dimensi Family to work development merupakan dimensi yang memiliki nilai mean empirik paling tinggi, dapat dikatakan bahwa guru meyakini bahwa keteribatannya dalam keluarga mengarahkan dirinya untuk menjadi individu yang lebih baik dari sisi pengetahuan, keterampilan dan perilaku.

\section{Gambaran Job Demands}

Berikut ini penjelasan variabel work-family enrichment (skala 1-5) pada tabel berikut:

Tabel 2. Gambaran mean variabel dan dimensi job demands

\begin{tabular}{ccccccc}
\hline No & Variabel/ & Nilai & Nilai & Mean & Std. & Interpretasi \\
& Dimensi & Minimum & Maksimum & & & \\
\hline & Job demands & 1,430 & 4,570 & 3,216 & 0,639 & Tinggi \\
1. & Quantitave Demands & 1,750 & 4,000 & 2,924 & 0,566 & Tinggi \\
2. & Cognitive Demand & 2,000 & 4,670 & 3,892 & 0,502 & Sangat Tinggi \\
3. & Emotional Demands & 2,000 & 5,000 & 3,200 & 0,665 & Tinggi \\
4. Demands for hiring & 1,670 & 5,000 & 3,225 & 0,737 & Tinggi \\
& Demotions & & & & & \\
\hline
\end{tabular}

Berdasarkan tabel di atas skor mean empirik tututan pekerjaan sebesar 3.216 termasuk ke dalam kategori tinggi. Hal ini berarti bahwa job demands guru dapat memberi tekanan pada guru jika dirasakan berlebihan. Dari ke empat dimensi Job demands, dimensi cognitive demand merupakan dimensi yang memiliki nilai mean empirik paling tinggi. Dapat dikatakan bahwa sebagian besar guru merasakan tuntutan tugas yang berkaitan dengan kognisi memerlukan usaha yang lebih keras, misalnya untuk menghasilkan ide-ide baru, mengharuskan mengingat banyak hal dan membuat keputusan-keputusan.

\section{Gambaran Job Resources}

Berikut ini penjelasan variabel work-family enrichment (skala 1-5) pada tabel berikut: Tabel 3. Gambaran mean variabel dan dimensi job resources

\begin{tabular}{ccccccc}
\hline No & $\begin{array}{c}\text { Variabel/ } \\
\text { Dimensi }\end{array}$ & $\begin{array}{c}\text { Nilai } \\
\text { Minimum }\end{array}$ & $\begin{array}{c}\text { Nilai } \\
\text { Maksimum }\end{array}$ & Mean & $\begin{array}{c}\text { Std. } \\
\text { Deviation }\end{array}$ & Interpretasi \\
\hline & Job resources & 2,090 & 4,820 & 3,275 & 0.587 & Sangat tinggi \\
\hline 1. & Meaning of work & 1,000 & 5,000 & 1,923 & 1,260 & Rendah \\
\hline 2. & Feedback & 2,000 & 5,000 & 3,915 & 0,891 & Tinggi \\
\hline 3. & Social support & 1,330 & 5,000 & 3,892 & 0,847 & Sangat tinggi \\
\hline 4. & Supervisory Coaching & 1,500 & 5,000 & 3,419 & 0,879 & Sangat tinggi \\
\hline
\end{tabular}


Berdasarkan tabel diatas skor mean empirik job resources sebesar 3,275 termasuk ke dalam kategori sangat tinggi. Hal ini berarti sebagian besar guru menggunakan sumber daya kerjanya berupa keterampilan mengajar. Namun demikian pada dimensi Meaning of work memiliki kategori rendah. Hal ini berarti sebagian besar guru belum sepenuhnya memahami makna dan pentingnya sebagai guru serta belum memunculkan motivasi instrinsiknya. Dimensi Social support merupakan dimensi yang tertinggi artinya dukungan sosial dari sesama kolega guru dan lingkungan menjadi hal sesuatu yang sumber daya yang mendukung profesi guru.

\section{Pengujian Hipotesis}

Pengujian hipotesis penelitian ini dilakukan melalui 3 langkah, yaitu langkah (1) pengujian peran job demands terhadap work-family enrichment, (2) pengujian peran job resources terhadap workfamily enrichment, (3) pegujian peran job demands dan job resources terhadap work-family enrichment. Langkah ke tiga merupakan pengujian hipotesis penelitian ini. Tujuan dilakukan pengujian hipotesis secara bertahap untuk mengetahui peran setiap variabel independen terhadap variabel dependen.

\section{Langkah 1. Pengujian job demands terhadap work-family enrichment}

Hasil pengujian hubungan job demands terhadap work-family enrichment menghasilkan koefisien (Beta standardized coefficient) sebesar $-0,245$ dan tidak signifikan $\mathrm{p}>0,05(\mathrm{p}=0,114)$. Dengan demikian, tidak terbukti terdapat hubungan job demands terhadap work-family enrichment.

Tabel 4. Hasil regresi hubungan job demands terhadap work-family enrichment

\begin{tabular}{cccc}
\hline work-family enrichment & $\beta$ & $t$ & $p$ \\
\hline & & 11.473 & 0.000 \\
Mean_JD & -0.245 & -1.617 & 0.114 \\
\hline
\end{tabular}

\section{Langkah 2. Pengujian job resources terhadap work-family enrichment}

Hasil pengujian hubungan job resources terhadap work-family enrichment menghasilkan koefisien (Beta standardized coefficient) sebesar $+0,275$ dan tidak signifikan $\mathrm{p}>0,05(0,075)$. Dengan demikian terbukti tidak terdapat hubungan job resources terhadap work-family enrichment.

Tabel 5. Hasil regresi hubungan job resources terhadap work-family enrichment

\begin{tabular}{cccc}
\hline work-family enrichment & $\beta$ & $t$ & $p$ \\
\hline & & 7.221 & 0.000 \\
Mean_JR & 0.275 & 1.829 & 0.075 \\
\hline
\end{tabular}

Langkah 3. Hipotesis Penelitian: Pengujian job demands dan sumber daya secara bersamasama terhadap work-family enrichment

Hasil pengujian hubungan job demands dan job resources secara bersama-sama terhadap workfamily enrichment menghasilkan koefisien (Beta standardized coefficient) sebesar -0,308 dan signifikan $\mathrm{p}<0,05(\mathrm{p}=0,043)$ untuk hubungan job demands terhadap work-family enrichment. Dan koefisien (Beta standardized coefficient) $+0,333$ dan signifikan $\mathrm{p}<0,05(\mathrm{p}=0,029)$. Dengan demikian hipotesis penelitian terbukti bahwa terdapat hubungan job demands dan job resources secara bersama-sama terhadap work-family enrichment. 
Tabel 6. Hasil regresi hubungan job demands dan job resources terhadap work-family

\begin{tabular}{lccc}
\hline work-family enrichment & $\beta$ & $t$ & $p$ \\
\hline & & 7.330 & 0.000 \\
Mean_JD & -0.308 & -2.094 & 0.043 \\
Mean_JR & 0.333 & 2.265 & 0.029 \\
\hline
\end{tabular}

Koefisien determinasi (Adjusted $R$ square) job demands dan job resources secara bersama-sama terhadap work-family enrichment sebesar 12,5\%. Artinya besarnya job demands dan job resources secara bersama-sama telah memengaruhi work-family enrichment sebesar 12,5\%, sedangkan sisanya dipengaruhi oleh variabel lain.

Tabel 7. Determinasi hubungan job demands dan job resources terhadap work-family enrichment

Model Summary

\begin{tabular}{l|c|r|c|r|}
\hline Model & $\mathrm{R}$ & R Square & $\begin{array}{c}\text { Adjusted R } \\
\text { Square }\end{array}$ & $\begin{array}{c}\text { Std. Error of } \\
\text { the Estimate }\end{array}$ \\
\hline 1 &, $408^{\mathrm{a}}$ &, 167 &, 125 &, 47999 \\
\hline
\end{tabular}
a. Predictors: (Constant), Mean_JR, Mean_JD
b. Dependent Variable: Mean_WFE

\section{KESIMPULAN DAN SARAN}

Berdasarkan pengujian hipotesis penelitian dapat disimpulkan bahwa job demands dan job resources secara bersama-sama berperan work-family enrichment pada guru sekolah. Konstribusi pengaruh ke dua variabel independen, yaitu job demands dan job resources, sebesar 12,5\%. Dengan demikian dapat dikatakan bahwa terdapat peran job demands dan job resources terhadap work-family enrichment pada guru. Kesimpulan penelitian ini menegaskan bahwa, job demands berhubungan negatif terhadap work-family enrichment. Artinya guru sekolah menjadi mengartikan bahwa job demands yang berlebihan akan mengurangi peran di keluarganya. Sedangkan job resources berhubungan positif terhadap work-family enrichment. Artinya semakin guru sekolah termotivasi dan terampil sebagai pendidik akan memperkuat peran di keluarganya.

Work-family enrichment dikonsepkan oleh Greenhaus dan Powell (2006) sebagai suatu keadaan tentang sejauh mana pengalaman dalam satu peran meningkatkan kualitas hidup di peran lainnya. Konsep tersebut diaplikasikan pada penelitian ini menjadi sejauh mana pengalaman peran sebagai guru sekolah meningkatkan kualitas di kehidupan keluarga guru. Dipertegas oleh Greenhaus dan Beutell (1985), konsep work-family enrichment berfokus pada hubungan positif dari kedua peran tersebut, artinya jika peran guru sekolah positif maka peran di keluarga juga positif. Dan hal dijelaskan oleh guru sekolah yang memiliki mean variabel work-family enrichment yang sangat tinggi. Dengan kata lain, peran sebagai guru memperkaya peran di keluarga guru.

Penelitian ini tentu tidak terlepas dari keterbatasan. Jumlah partisipan yang tergolong kecil dan hanya menggunakan sampel dari sekolah sejenis membuat generalisasi penelitian perlu diperkuat lagi. Dengan kata lain, penelitian ini sebagai penelitian awal yang perlu diperdalam dan dipertajam kembali. 
Keterbatasan penelitian ini juga hanya menggali peran job demands dan job resources terhadap work-family enrichment. Dengan hanya baru memprediksi $12,5 \%$ menunjukkan masih banyak variabel lain yang perlu dipertimbangkan. Contoh self esteem karena berhubungan dengan meaning of work, kualitas kehidupan kerja karena berhubungan dengan kepuasan kerja (Carlson, et al., 2011), copying stress berhubungan dengan job demands dan motivasi atau work passion berhubungan dengan job resources.

Bagi guru, hasil penelitian ini dapat disikapi dengan menumbuhkan motivasi yang kuat untuk bisa terus melakukan tugas dan tanggung jawabnya baik di sekolah maupun di dalam kehidupan berkelurga. Selain itu melalui manajemen waktu yang baik, para guru tidak harus banyak meninggalkan aktivitas keluarga dalam memenuhi tanggung jawab pekerjaannya di sekolah.

Bagi keluarga, hasil penelitian ini dapat disikapi dengan memberikan dukungan kepada pasangan atau anggota keluarga yang bekerja sebagai guru, seperti dengan mendengarkan cerita-cerita seputar siswa didiknya ataupun bertukar pikiran mengenai hal-hal positif sebagai pendidik diupayakan dapat dicontoh untuk keluarganya. Pengertian peran sebagai keluarga bisa sebagai bapak, ibu, anak, kakek dan nenek dan lainnya yang dalam lingkup keluarga.

\section{Ucapan Terima Kasih (Acknowledgement)}

Penulis mengucapkan terima kasih kepada Sekolah $\mathrm{X}$ yang telah mengijinkan untuk melakukan penelitian. Penulis juga mengucapkan terima kasih kepada guru di Sekolah X. yang telah bersedia menjadi responden.

\section{REFERENSI}

Bakker, A. B., \& Demerouti, E. (2014). Burnout and work engagement: The JD - R approach. Annual Review of Organizational Psychology and Organizational Behavior, 1, 389-411. Diakses dari https://doi.org/10.1146/annurev-orgpsych-031413-091235

Bakker, A. B., Hakanen, J. J., Demerouti, E., Xanthopoulou, D. (2007). Job resources boost work engagement, particularly when job demands are high. Journal of Educational Psychology, 99(2), 274 - 284. Diakses dari doi: 10.1037/0022-0663.99.2.274

Carlson, D. S., Ferguson, M., Kacmar, K. M., Grzywacz, J. G., \& Whitten, D. (2011). Pay it forward: The positive crossover effects of supervisor work-family enrichment. Journal of Management, 37(3), 770-789. Diakses dari https://doi.org/10.1177/0149206310363613

Carlson, D. S., Kacmar, K. M., Wayne, J. H., \& Grzywacz, J. G. (2006). Measuring the positive side of the work - family interface: Development and validation of a work - family enrichment scale. Journal of Vocational Behavior, 68, 131-164. Diakses dari https://doi.org/10.1016/j.jvb.2005.02.002

Greenhaus, J. H., \& Beutell, N. J. (1985). Sources of conflict between work and family roles. Academy of Management Review, 10(1), 76-88. Diakses dari https://doi.org/10.5465/amr.1985.4277352

Greenhaus, J. H., \& Powell, G. N., (2006). When work and family are allies: A theory of work family enrichment. Academy of Management Review, 31(1), 72-92. Diakses dari https://doi.org/10.5465/amr.2006.19379625

Lestari, W., \& Zamralita. (2017). Gambaran job demands (job demands) dan dukungan pekerjaan (job resources) pada pegawai Institusi X DKI Jakarta. Jurnal Muara Ilmu Sosial, Humaniora, dan Seni. 1(2), 134-143. Diakses dari 10.24912/jmishumsen.v1i2.983

Pejtersen, J. H., Kristensen, T. S., Borg, V., \& Bjorner, J. B. (2010) The second version of the copenhagen psychosocial questionnaire. Scandinavian Journal of Public Health, 38(3), 824. Diakses dari https://doi.org/10.1177/1403494809349858 
Pemendikbud Nomor 15 Tahun 2018. Peraturan Menteri Pendidikan dan Kebudayaan Republik Indonesia. tentang Pemenuhan Beban Kerja Guru, Kepala Sekolah, dan Pengawas Sekolah.

Schaufeli, W. B., \& Bakker, A. B. (2004). Job demand, job resources, and their relationship with burnout and engagement: A multi-sample study. Journal of Organizational Behavior, 25, 293 - 315. Diakses dari doi: 10.1002/job.248. 